\title{
As representações sociais de estudantes universitários a respeito das cotas para negros e pardos nas universidades públicas brasileiras
}

\section{College students social representations on racial quotas in public universities in Brazil}

\section{Denis Giovani Monteiro Naiff*}

Professor Adjunto do Departamento de Psicologia da Universidade Federal Rural do Rio de Janeiro/UFRRJ - Seropédica, RJ, Brasil

\section{Luciene Alves Miguez Naiff **}

Professora Titular do Programa de Pós-Graduação Strito-Sensu em Psicologia da Universidade Salgado de Oliveira/UNIVERSO - Niterói, RJ, Brasil

\section{Marcos Aguiar de Souza***}

Professor Adjunto do Departamento de Psicologia da Universidade Federal Rural do Rio de Janeiro/UFRRJ - Seropédica, RJ, Brasil

\begin{abstract}
Resumo
É bastante atual e polêmico o debate existente sobre a questão das cotas para negros e pardos nas universidades públicas brasileiras. Dentro deste contexto, a Universidade Federal Rural do Rio de Janeiro - UFRRJ - tem discutido com a sua comunidade a implantação de cotas raciais em seu vestibular. Este trabalho teve como objetivo conhecer as representações sociais que os alunos da UFRRJ possuem sobre as cotas para negros e pardos na Universidade. Foram entrevistados 100 alunos dos cursos de licenciatura que foram submetidos a uma tarefa de evocação livre perante o termo indutor "Cotas para negros e pardos nas Universidades". Os dados foram analisados com auxilio do programa de computador EVOC 2003. Os resultados apontam para uma atitude majoritariamente contrária contrastando com uma representação estruturada em torno de elementos justificadores da implantação das cotas, o que pode estar indicando a existência de uma zona muda das representações sociais sobre o objeto estudado.
\end{abstract}

Palavras-Chave: Representações sociais, Ação afirmativa, Universidades públicas, Racismo.

\footnotetext{
Abstract

Today there is a constant debate concerning racial quotas for non-white students in public universities in Brazil. For instance the Federal Rural University of Rio de Janeiro (UFRRJ) is carrying out a public debate on the proposal of establishing racial quotas for the vestibular exam (similar to the SAT) with the main objective of understanding what are the social
} 
representations of the students in this particular subject. The debate was followed by interviews with 100 students that were asked to talk freely about their ideas and thoughts on racial quotas. The data was analyzed using the computer program EVOC 2003, among other methodologies. Considering social representation analysis the results show that the majority of the interviewees agree with racial quotas theoretically but on practical terms they are against it. This contradiction is defined as "mute zone" where you have to identify other forms of extracting the information you need other than using mainly the discourse.

Keywords: Social representations, Affirmative action, Public universities, Racism.

\section{I ntrodução}

\subsection{As cotas para negros e pardos nas universidades públicas brasileiras: um breve histórico}

É bastante atual e polêmico o debate existente sobre a questão das cotas para negros e pardos nas universidades públicas brasileiras. Tanto nos meios intelectuais, como na sociedade em geral, múltiplos posicionamentos têm surgido sobre esse tema, obtendo visibilidade na imprensa escrita, especialmente, nos jornais de grande circulação no país. Estas diversas posições encontram justificativas nos variados argumentos existentes a favor ou contra as cotas como políticas de ação afirmativa (TRAGTENBERG; BASTOS; NOMURA; PERES, 2006; BRANDÃO, 2005; MUNANGA, 2004).

Embora seja longa a história dos movimentos sociais a favor da melhoria das condições de vida e cidadania dos negros no Brasil, a reivindicação de políticas afirmativas no campo da educação superior se consolidou apenas recentemente, mais precisamente a partir da década de 1990. Autores como Munanga (2003) explicam que, apesar de algumas pequenas iniciativas ocorridas no passado, as organizações e movimentos de defesa dos negros brasileiros concentraram-se mais, até a década de 1980, na denúncia do racismo e na discriminação presentes em nossa sociedade, do que em proposições de políticas de ação afirmativa. Uma das razões alegadas para certo atraso nessa reivindicação, quando comparamos - Brasil com os Estados Unidos da América, onde ações afirmativas acontecem desde a década de 1960, foi a predominância ao longo do século XX do "mito da democracia racial" no imaginário brasileiro. Mito este, influenciado em parte pelas conclusões a respeito da constituição miscigenada da sociedade brasileira presentes na clássica obra do sociólogo Gilberto Freire "Casa Grande e Senzala" de 1933. Posteriores estudos de inspiração "Freireana" buscaram relativizar os preconceitos e discriminações de raça existentes no Brasil, ao mesmo tempo em que defendiam a mestiçagem como 
padrão unificador do povo brasileiro (RIBEIRO, 1995). Seguindo esta linha de raciocínio, Ianni (2004, p. 9) advoga que:

A hipótese de que o Brasil seria, ou seja uma democracia racial foi adotada com muito entusiasmo e a proposta era apresentar dados substantivos que comprovassem essa tese. Ou seja, de que no Brasil havia preconceito de classe e de que o preconceito racial era apenas um ingrediente de preconceito de classe, tese recorrente de análises oriundas das obras de Gilberto Freire.

Nesse sentido, as desigualdades raciais existentes no Brasil poderiam ser explicadas unicamente através da dimensão econômica, já que haveria no país uma igualdade étnico-racial. A existência de uma suposta "identidade nacional" que vê o Brasil como um país de mestiços e é caracterizada pela convivência pacífica e mistura harmoniosa de diferentes raças e etnias. Segundo Silvério (2003) esta construção social de que no Brasil não há negros, somente mestiços, teve entre outras conseqüências nefastas banalizar as práticas discriminatórias cotidianas e reforçar a invisibilidade deste mesmo negro perante a sociedade.

Apesar de comporem $45 \%$ dos brasileiros, a população negra e parda, que conclui o ensino superior representa apenas $2 \%$ e $12 \%$ daquele total, respectivamente (MOEHLECKE, 2004; SILVA, 2006) e "a proporção de negros entre as pessoas com 12 anos ou mais de estudo é de apenas $2,8 \%$, quase quatro vezes menos que os brancos na mesma faixa" (HENRINGER, 2002, p.59). Guimarães (2003) aponta como algumas causas da pequena absorção da população negra e parda no ensino superior: a) pobreza; b) qualidade da escola pública; c) preparação insuficiente; d) pouca persistência (pouco apoio familiar e comunitário; e) as formas de seleção utilizadas no vestibular (o exame vestibular não deixa espaço para que outras qualidades e potencialidades dos alunos sejam avaliadas).

$\mathrm{Na}$ busca de superar esse déficit, a partir de 2001, algumas universidades brasileiras públicas (UERJ e UENF, no Rio de Janeiro; UnB em Brasília, por exemplo), passaram a oferecer uma porcentagem de vagas, em seus vestibulares, a serem disputadas somente por candidatos negros e pardos (MAGGIE; FRY, 2004; MOEHLECKE, 2004). Partindo da premissa de que a população negra brasileira foi, e continua sendo, alvo de inúmeras formas de discriminação racial, a reivindicação por cotas nas formas de ingresso nas universidades públicas seria uma forma de compensação pelas perdas geradas a esse grupo, possuindo como utopia uma futura igualdade sócio-econômica real entre negros e brancos na sociedade brasileira (MUNANGA, 2003).

Através da implantação das cotas buscou-se possibilitar a esses sujeitos seu passaporte aos níveis econômicos, sociais e culturais mais elevados da sociedade, gerando, desta forma, o surgimento de uma classe social média e alta estabelecida, que pudesse se 
transformar em identitária da população negra, similar ao fenômeno que aparentemente vem ocorrendo nas últimas décadas nos Estados Unidos da América (GUIMARÃES, 2003).

Embora haja o reconhecimento, por parte de militantes, em prol dos direitos dos negros e por parte do meio intelectual e político, da necessidade de se atender à demanda pela maior diversidade étnica nas universidades brasileiras, existe certa uniformidade nos argumentos de que as ações afirmativas no Brasil, estas com características mais universais, confundiram-se ou ficaram restritas às propostas de cotas, o que para alguns autores teriam provocado a forte resistência (VERÍSSIMO, 2003).

As políticas de cotas universitárias encontram amplo amparo nas diretrizes do atual governo brasileiro para o ensino superior (MEC, 2007); entretanto esta política pública ainda submete-se a severas resistências em amplos setores da sociedade brasileira. Os principais argumentos contrários caminham na direção da dimensão econômica para explicar as desigualdades existentes na população estudantil das universidades públicas (FRY; MAGGIE; MAIO, MONTEIRO !; SANTOS, 2007; KAMEL, 2006): ao invés de criar cotas raciais, o governo deveria privilegiar a melhoria do ensino fundamental e médio públicos, pois sua baixa qualidade seria a principal geradora das distorções encontradas no ensino superior. No máximo, advogam políticas afirmativas para a população pobre oriunda da escola pública, sem privilegiar um estrato racial específico da mesma (BERNARDINO, 2002). Outro argumento utilizado, este com viés mais conservador, afirma que o acesso às universidades se dá pelo critério de mérito, e que a adoção das cotas o violaria, podendo gerar no futuro uma perda significativa da qualidade do ensino $e$ consequentemente, dos futuros profissionais formados (MUNANGA, 2004). Finalmente, a miscigenação brasileira tornaria praticamente impossível classificar quem, em nosso país, não seria negro ou pardo, o que dificultaria a seleção dos beneficiados e geraria injustiças no processo (MAGGIE, 1996; MAIO; SANTOS, 2005). Esta última assertiva tem gerado prolíficos debates no meio intelectual brasileiro, em especial na antropologia e na sociologia quanto ao emprego da análise de características fenotípicas através da fotografia dos candidatos, aliados à auto-classificação dos mesmos, como um dos critérios para definir quem deve ser incluído nas cotas:

O que conta no nosso cotidiano ou que faz parte de nossas representações sociais do negro, do branco, do índio, do amarelo e do mestiço não se coloca no plano do genótipo, mas sim, do fenótipo, num país onde, segundo Oracy Nogueira, o preconceito é de marca e não de origem. (MUNANGA, 2003, P. 123)

A Universidade Federal Rural do Rio de Janeiro (UFRRJ) tem estado atenta a esse contexto e vem promovendo vários debates e consultas à sua comunidade acadêmica com respeito à possibilidade de 
implantação de uma política de reservas de vagas no ingresso em seus cursos de graduação, para negros e pardos.

No Brasil, as pesquisas sobre a recepção de políticas afirmativas apenas se iniciam, mas já apontam para a necessidade de conhecer melhor o "caldo" das crenças, preconceitos e representações sociais que cercam o assunto e subsidiam em muitos momentos as resistências à implantação das políticas públicas de democratização do ensino superior público (SILVÉRIO, 2003; VALENTE, 2002; FRY, MAGGIE, GRIN, 2005). Desta forma, entendemos que conhecer e compreender as representações sociais compartilhadas em seu alunado sobre a temática supracitada, podem embasar futuras estratégias de implementação e consolidação de ações afirmativas na universidade pública brasileira.

Considerando como referencial teórico-metodológico a teoria das representações sociais, criada pelo psicólogo social francês Serge Moscovici (1961/1979), podemos dizer que, no Brasil, representações compartilhadas sobre os negros, presentes no imaginário da população em geral, muitas vezes entram em choque com as novas representações construídas e defendidas pelos militantes e simpatizantes na luta em defesa dos direitos da comunidade negra.

\section{2. A teoria das representações sociais}

É no universo sociocultural que estão e são continuamente produzidas as representações sociais. Se quisermos compreender por que uma pessoa se comporta de um jeito e não de outro devemos ver as relações sociais embutidas em seu cotidiano. Nossas reações frente a outras pessoas e objetos sociais estão em grande parte mediadas pela percepção e pelas representações sociais que fazemos dela ( $\mathrm{MOSCOVICl}, 2003$ ).

O universo educacional é atualmente um grande foco de pesquisas nas áreas da educação e da psicologia, com um crescente incremento, principalmente no Brasil, dos estudos que utilizam o referencial da teoria das representações sociais em busca de auxílio neste entendimento. Alves-Mazzotti (2005, p.142) aponta para o fato de que a teoria das representações sociais vem sendo acolhida como um caminho promissor

Por suas relações com as práticas, por seu papel na formação das identidades, pelas possibilidades que oferecem de antecipar hipóteses sobre comportamentos e trajetórias, bem como de identificar conflitos entre os sentidos atribuídos ao mesmo objeto pelos diferentes atores sociais envolvidos.

Segundo Gilly (2001, p.322) o crescente interesse do estudo das representações sociais na área da educação se deve principalmente à sua relevância social e o quanto mobiliza os atores envolvidos "dada 
a importância crucial que lhe atribuem as diferentes partes envolvidas (administradores, dirigentes centrais, agentes do sistema e usuários)".

Essas considerações servem para ilustrar como atores sociais, a partir de algumas informações de origem e natureza diversa, organizam, interpretam, e constroem algumas representações mútuas que irão mediar suas relações. O conceito de representação social designa uma forma específica de conhecimento, o saber do senso comum, cujos conteúdos manifestam a operação de processos generativos e funcionais socialmente marcados; mais amplamente, designa uma forma de pensamento social. Uma definição muito bem aceita dentro do campo e que resume suas principais características é dada por Jodelet (2001, p.22), na qual as representações sociais são "uma forma de conhecimento, socialmente elaborada e partilhada, com um objetivo prático, e que contribui para a construção de uma realidade comum a um conjunto social".

Falar em representações sociais implica em considerá-las enquanto emergentes na dimensão simbólica da vida social, pois servem para agir sobre o mundo e sobre os outros. As representações sociais nascem no cotidiano, nas interações que estabelecemos, seja na família, no trabalho, na escola, nas relações com a saúde, entre outras dimensões da vida social, ou seja, onde quer que exista uma realidade a ser apropriada e partilhada.

A formação de representações sociais, portanto, agrega duas principais características: em primeiro lugar a premissa de que as representações sociais tem o objetivo de transformar o não-familiar em familiar, e em segundo lugar é uma modalidade, segundo Moscovici (1984), que tem por função direcionar o comportamento e a comunicação.

As representações sociais, para Abric (1998), têm um papel fundamental na dinâmica das relações sociais e nas práticas porque respondem a quatro funções essenciais: (a) de saber, por permitirem compreender e explicar a realidade; (b) identitárias, ao definirem a identidade social e permitirem a salvaguarda da especificidade dos grupos; (c) de orientação, já que guiam os comportamentos e as práticas; e (d) justificatórias, pois permitem justificar a posteriori as tomadas de posição e os comportamentos.

Assim, o enfoque dado através das representações sociais nos possibilita conhecer as formas de saber, práticas e emoções que estão sendo elaboradas e partilhadas e que apontam para atitudes e práticas exercidas pelos grupos de pertença de partilham destes conteúdos socialmente elaborados (WAGNER, 1998).

Este artigo tem como objetivo conhecer, através de uma abordagem estrutural, as representações sociais que alunos de cursos de licenciatura da Universidade Federal Rural do Rio de Janeiro - 
UFRuraIRJ compartilham sobre a política de cotas para negros e pardos no ingresso de novos alunos.

\section{Metodologia}

Participaram da pesquisa 100 estudantes selecionados aleatoriamente nos cursos de licenciatura da Universidade Federal Rural do Rio de Janeiro - UFRRJ. Os sujeitos responderam a um breve questionário com questões relacionadas às suas atitudes, nível de conhecimento e grau de trocas comunicacionais sobre o tema das cotas, além de serem submetidos a uma tarefa de evocação livre na qual foi solicitado que expressassem espontaneamente cinco palavras ou expressões que Ihes viessem imediatamente à lembrança quando apresentávamos o termo indutor "Cotas para negros e pardos na universidade pública". Em uma segunda etapa foi pedido aos sujeitos que hierarquizassem por grau de importância as palavras ou expressões evocadas anteriormente. Essa técnica combinada aproveita o material bruto nascido da associação livre e o organiza cognitivamente, permitindo uma reavaliação da ordem de evocação, de acordo com indicação de Abric (2003) que advoga pela substituição do "rang de aparição" pelo "rang de importância" como produto final desta técnica de coleta de dados.

As respostas foram submetidas a uma análise com auxilio do programa de computador EVOC 2003â (Ensemble de programmes permettant l'analyse des evocations), cuja lógica procura combinar a freqüência com que as palavras e expressões são emitidas pelos sujeitos com a ordem em que cada sujeito as evoca, permitindo apreender quais os elementos das representações sociais são presentes de forma mais central na produção discursiva dos sujeitos.

A FIGURA 1 apresenta uma esquematização da distribuição dos resultados gerados pela técnica da evocação livre. O cruzamento da freqüência média das evocações com a ordem média em que foram evocadas gera quatro quadrantes, pelos quais os elementos evocados se distribuem. A técnica advoga que no quadrante superior esquerdo se alocariam os possíveis elementos centrais e no quadrante inferior direito estariam os elementos claramente periféricos nessa representação. A lógica subjacente à técnica empregada é que os elementos que ao mesmo tempo tenham sido mais freqüentes e mais prontamente evocados teriam maior probabilidade de pertencerem ao núcleo central da representação social estudada (VERGĖS, 1994; 2005; OLIVEIRA; MARQUES; GOMES; TEIXEIRA, 2005).

No segundo quadrante encontramos a primeira periferia composta pelos elementos periféricos mais importantes da representação, possuidores de freqüência elevada, mas que foram mais tardiamente evocados. O terceiro quadrante seria composto pelos elementos de 
contraste, que foram considerados importantes pelos sujeitos apesar de sua baixa freqüência total no corpus de análise. Abric (2003, p. 64) considera que este quadrante pode tanto "revelar a existência de um sub-grupo minoritário portador de uma representação diferente", como ser apenas composto de elementos complementares da primeira periferia. No quarto quadrante, teríamos os elementos claramente periféricos da representação, pouco e tardiamente evocados.

\begin{tabular}{|c|c|c|}
\hline Ordem & média & de \\
\hline \multirow[t]{2}{*}{$\begin{array}{l}\text { Frequência } \\
\text { média }\end{array}$} & $\begin{array}{l}1^{0} \text { quadrante } \\
\text { Elementos do Núcleo } \\
\text { Central } \\
\text { prontamente evocados } \\
+ \text { alta frequência }\end{array}$ & $\begin{array}{l}2^{0} \text { quadrante } \\
\text { Elementos da } 1^{a} \\
\text { periferia } \\
\text { tardiamente } \\
\text { evocados }+ \text { alta } \\
\text { frequência }\end{array}$ \\
\hline & $\begin{array}{l}3^{0} \text { quadrante } \\
\text { Elementos } \\
\text { contraste } \\
\text { prontamente evocados } \\
+ \text { baixa frequência }\end{array}$ & $\begin{array}{l}4^{0} \text { quadrante } \\
\text { Elementos da } 2^{a} \\
\text { periferia } \\
\text { tardiamente } \\
\text { evocados }+ \text { baixa } \\
\text { frequência }\end{array}$ \\
\hline
\end{tabular}

Figura 1: Representação esquemática da distribuição das cognições das representações sociais no modelo de evocação livre.

\section{Resultados}

$\mathrm{Na}$ amostra estudada, $68 \%$ dos alunos declararam serem contrários à implantação de cotas para ingresso de negros e pardos na universidade pública brasileira. Em relação a sua própria imagem racial, $46 \%$ declararam-se pardos; $20 \%$ negros; $32 \%$ brancos e $2 \%$ como amarelos; ou seja, $66 \%$ passíveis de serem beneficiados pelo projeto de cotas em discussão.

A análise das evocações (FIGURA 2) aponta para um provável núcleo central da representação social das cotas para negros e pardos nas universidades públicas estruturado em torno de elementos justificadores de sua implantação, amplamente divulgados pelos defensores da proposta, quais sejam: a possibilidade de combate ao racismo e ao preconceito historicamente presentes em nossa sociedade, associados a uma desigualdade social estrutural advinda desta realidade.

Entretanto, corroborando o posicionamento majoritariamente contrário do grupo à implantação da proposta, observamos cognições estruturadas na primeira periferia refletindo à noção de que o processo é injusto, refletindo muito mais uma educação deficiente 
nos níveis fundamentais e médios, do que dimensões racializadas organizadas no bojo dos processos sócio-culturais societários.

Essas dimensões contrárias aparecem de forma mais marcante na análise dos elementos periféricos do quadrante inferior esquerdo, refletindo inclusive claras estruturas atitudinais, quais sejam: o entendimento de que o projeto constitui um erro associado à possibilidade de gerar discriminação ou segregação racial no universo universitário, ou simplesmente a atitude explicitamente contrária reflete o posicionamento observado anteriormente na amostra estudada.

\begin{tabular}{|c|c|c|c|c|}
\hline $\begin{array}{l}\text { Preconceito } \\
\text { Racismo } \\
\text { Desigualdade- } \\
\text { social }\end{array}$ & $\begin{array}{l}51 \\
30 \\
27\end{array}$ & $\begin{array}{l}1,86 \\
2,50 \\
2,70\end{array}$ & $\begin{array}{l}\text { Educação-fraca } \\
\text { Injustiça }\end{array}$ & $\begin{array}{l}29 \\
3,14 \\
33 \\
3,28\end{array}$ \\
\hline & & & \multicolumn{2}{|l|}{ Frequência $\geq 23$} \\
\hline Frequência $<23$ & & & & \\
\hline $\begin{array}{l}\text { Discriminação } \\
\text { Erro } \\
\text { Sou-contra } \\
\text { Exclusão-social } \\
\text { Segregação }\end{array}$ & $\begin{array}{l}21 \\
17 \\
13 \\
11 \\
9\end{array}$ & $\begin{array}{l}1,86 \\
2,77 \\
1,77 \\
1,91 \\
2,44\end{array}$ & Pobreza & $\begin{array}{l}17 \\
3,70\end{array}$ \\
\hline
\end{tabular}

Figura 2 - Representação de Cotas para negros e pardos nas universidades públicas brasileiras em estudantes de licenciatura da UFRRJ $(n=100)$.

A FIGURA 3 apresenta a análise das evocações apenas dos sujeitos que se auto-declararam como negros ou pardos. Chama imediatamente a atenção $o$ fato de que a percepção do processo como injusto deixa de ser periférico e passa a ser encontrado como elemento constituinte de um provável núcleo central da estrutura da representação social estudada, associado aos elementos justificadores da implantação do projeto já anteriormente encontradas na amostra original. O entendimento de que os projetos de cotas são desnecessários aparece como elemento periférico presente no quadrante inferior esquerdo, ocupando o lugar anteriormente presente pelo combate à exclusão-social e à segregação, que deixam de ser cognições presentes nas evocações analisadas. As dimensões contrárias permanecem presentes. 


\begin{tabular}{|c|c|c|c|c|}
\hline $\begin{array}{l}\text { Preconceito } \\
\text { Injustiça } \\
\text { Racismo } \\
\text { Desigualdade- } \\
\end{array}$ & $\begin{array}{l}31 \\
22 \\
18 \\
18\end{array}$ & $\begin{array}{l}1,90 \\
2,64 \\
2,50 \\
2,83\end{array}$ & Educação-fraca & $\begin{array}{l}20 \\
3,25\end{array}$ \\
\hline & & & \multicolumn{2}{|l|}{ Frequência $\geq 15$} \\
\hline Frequência $<15$ & & & & \\
\hline $\begin{array}{l}\text { Erro } \\
\text { Discriminação } \\
\text { Sou-contra } \\
\text { Desnecessário }\end{array}$ & $\begin{array}{l}14 \\
10 \\
11 \\
6\end{array}$ & $\begin{array}{l}2,64 \\
2,00 \\
1,64 \\
2,33\end{array}$ & $\begin{array}{l}\text { Incapacidade } \\
\text { Pobreza }\end{array}$ & $\begin{array}{l}17 \\
3,70 \\
14 \\
3,71\end{array}$ \\
\hline
\end{tabular}

Figura 3 - Representação de Cotas para negros e pardos nas universidades públicas brasileiras em estudantes auto-identificados como negros e pardos de licenciatura da UFRuraIRJ $(n=66)$.

\section{Considerações Finais}

$\mathrm{Na}$ educação superior o governo Lula tem priorizado propostas visando uma maior diversidade étnica nas universidades públicas brasileiras, principalmente através de propostas de ações afirmativas visando a comunidade negra. Um exemplo atual podemos encontrar no UNIAFRO - Programa de Ações Afirmativas para a População Negra nas Instituições Públicas de Educação Superior - programa patrocinado pelo Ministério da Educação, através da Secretaria de Ensino Superior e que visa apoiar e incentivar o fortalecimento e a institucionalização das atividades dos Núcleos de Estudos AfroBrasileiros-NEABs ou grupos correlatos das Instituições Públicas de Educação Superior, contribuindo para a implementação de políticas de ação afirmativa voltadas para a população negra e estimular a integração das ações de implantação das diretrizes curriculares étnico-raciais, conforme o Parecer CNE/CP 003/2004 e a Resolução $\mathrm{CNE} / 001 / 2004$, em todos os níveis de ensino. Neste cenário, as universidades públicas brasileiras têm buscado desenvolver estratégias de esclarecimento visando fomentar o debate e encontrar estratégias próprias para aumentar o nível de inclusão presente em suas comunidades, tradicionalmente acusadas de elitismo.

Estudando amostras representativas de toda a comunidade acadêmica da UFRJ; Fry, Maggie e Grin (2005) encontraram que a maioria dos sujeitos considerava mais injusto a adoção de reserva de 
vagas para pessoas negras, do que para pessoas pobres e oriundas de escolas públicas, por entenderem que as cotas iriam acirrar a discriminação racial. Dados similares também são apresentados neste estudo, no qual $68 \%$ dos alunos declararam-se contrários a implantação deste modelo de política compensatória.

Quando olhamos para os dados oriundos da estrutura representacional, aparentemente defrontamos com uma contradição: O provável núcleo central estrutura-se diante de uma imagem ideologizada referente às justificativas empregadas para a implantação das cotas para negros e pardos (racismo e preconceito), enquanto que as dimensões contrárias aparecem apenas de forma periférica. Esta construção muda conforme analisamos apenas os dados oriundos da amostra composta pelos auto-identificados como negros e pardos. Isto nos remete às reflexões construídas sobre os processos de produção e circulação das representações sociais presentes em Jodelet (2001, p.33) que apontam para a necessidade de contextualizar os grupos que representam um determinado objeto social: "Quem sabe e de onde sabe? O que e como sabe? Sobre o que sabe e com que efeitos?". Esta contextualização nos auxiliam no entendimento do porque do discurso meritocrático estar presente de forma tão intensa no material evocado pelo estrato beneficiado pela introdução do projeto de cotas em questão. Falamos aqui de sujeitos que conseguiram, apesar de todas as dificuldades estruturais já anteriormente relatadas, adentrar no ensino superior público sem utilizar o sistema de cotas. Logo, sua inserção foi regida pelos mesmos princípios que servem a todos, isto é, o mérito. Desse modo, podem estar compartilhando a noção de que se conseguiram, outros também em situação similar podem fazer o mesmo e entendem como injusto que indivíduos possam beneficiar-se de ações afirmativas que os levariam para a universidade pública através de um esforço menor que o empregado por eles.

Entretanto, alguns cenários sociais também são fortemente carregados de pressões normativas, no qual se incluem as questões discriminatórias, levando aos sujeitos a constituir um campo representacional formado por elementos que resistem a serem verbalizados. Este campo representacional é denominado de "zona muda das representações sociais" e pode ser definido como

"um subconjunto específico de cognições ou de crenças, que, mesmo sendo disponíveis, não são expressadas pelos sujeitos nas condições normais de produção e que se forem expressas (notadamente em certas situações) poderiam questionar os valores morais ou as normas valorizadas pelo grupo" (GUIMELLI; DESCHAMPS, 2000).

Desta forma, uma das hipóteses explicativas para a aparente contradição entre cognições favoráveis constituintes de um provável núcleo central da representação social e uma atitude majoritariamente desfavorável é que os elementos contra-normativos 
estariam presentes em uma zona muda da representação social sobre cotas para negros e pardos na universidade pública nos alunos estudados na UFRRJ .

Finalizando, advogamos a necessidade de mais estudos psicossociológicos que auxiliem 0 entendimento dos sentidos envolvidos na produção e transformação das representações sociais relacionadas à temática aludida, visando formatar estratégias de intervenção comunicacional ou de influência social inspiradas na teoria das minorias ativas, por exemplo, destinadas a qualificar o debate necessário no ambiente universitário sobre as políticas de inclusão social que buscam transformar a universidade em um ambiente cada vez mais representativo da sociedade ao qual pertence.

\section{Referências Bibliográficas}

ABRIC, J. C. Prácticas sociales, representaciones sociales. In: JEANCLAUDE ABRIC (Ed.). Prácticas socials y representacioes. México D. F.: Ediciones Coyoacán, 2001a. p. 195-214.

. Las representaciones socials: aspectos teóricos. In: JEANCLAUDE ABRIC (Ed.). Prácticas socials y representacioes. México D. F.: Ediciones Coyoacán, 2001b. p. 11-32.

- La recherche du noyau central et la zone muette des représentations sociales. In: JEAN-CLAUDE ABRIC (Ed.) Méthodes d'étude des représentations sociales. Paris: Érès, 2003. p. 59-80. BERNARDINO, J. Ação afirmativa e a rediscussão do mito da democracia racial no Brasil. Estudos Afro-Asiáticos, Rio de Janeiro, ano 24, n.2, p. 247-273, 2002.

BRANDÃO, C. F. As cotas na universidade pública brasileira: será esse o caminho? Campinas: Autores Associados. 2005.

DURHAM, E. Desigualdade educacional e cotas para negros nas universidades. Novos Estudos, São Paulo, N 66, p.70-86, 2003.

FRY, P.; MAGGIE, Y.; GRIN, M. Percepções de desigualdade, equidade e justice social no ensino superior: o caso da UFRJ, 2005.

Disponível em:

$<$ http://www. observa. ifcs. ufrj. br/relatorios/relatoriopesquisaUFRJ-

sensus3.pdf> Acesso em 01 jul 2007.

GUIMELLI, C.; DESCHAMPS, J. C. Effets de contexte sur la production d'associations verbales: les cas des représentations sociales dês Gitans. Cahiers Internationaux de Psychologie Sociale, Paris, v. 47-48 n.3-4, p. 44-54, 2000.

HENRIGER, R. Desigualdades raciais no Brasil: síntese dos indicadores e desafios no campo das políticas públicas. Cadernos de Saúde Pública, Rio de Janeiro, V. 18, p. 57-65, 2002. 
IANNI, O. Preconceito racial no Brasil. Estudos Avançados, São Paulo, v. 18, n.50, p. 6-20. 2004.

JODELET, D. Representações sociais: um domínio em expansão. In: D. JODELET. (Ed). As representações sociais. Rio de Janeiro: EDUERJ, 2001. p. 17-44.

MAGGIE, Y. Aqueles a quem foi negada a cor do dia: as categorias cor e raça na cultura brasileira. In: M. C. MAIO; R. V. SANTOS (Orgs.). Raça, ciência e sociedade. Rio de Janeiro: Fiocruz/CCBB, 1996. p. 225-234.

MAGGIE, Y.; FRY, P. A reserva de vagas para negros nas universidades brasileiras. Estudos Avançados, São Paulo, v. 18, n. 50, p. 67-80. 2004.

MAIO, M.C.; SANTOS, R.V. Política de cotas raciais, os "olhos da sociedade" e os usos da antropologia: o caso do vestibular da Universidade de Brasília (UnB). Horizontes Antropológicos, Porto Alegre, v. 11 n. 23, p. 181-214, 2005.

MOEHLECKE, S. Ação afirmativa no ensino superior: entre a excelência e a justiça racial. Educação e Sociedade, Campinas, v. 25, n.8, p. 757-776, 2004.

Ação afirmativa: história e debates no Brasil. Cadernos de Pesquisa, São Paulo, n. 117, p. 197-217, 2002.

MOSCOVICl, S. El psicoanálisis, su imagen y su público. Buenos Aires: Editorial Huemul. 1979.

The phenomenon of social representations. In:

Social representations. Cambridge: Cambridge University Press, 1984. p. 03-70.

- A história e a atualidade das representações sociais. In: _-_. (Org.): Representações sociais: Investigações em psicologia social. Petrópolis: Vózes, 2003, p.167-214.

MUNANGA, K. Políticas de ação afirmativa em benefício da população negra no Brasil: um ponto de vista em defesa de cotas. In: GONÇALVES E SILVA, P. B.; SILVÉRIO, V. R. Educação e ações afirmativas: entre a injustiça simbólica e a injustiça econômica. Brasília: Instituto Nacional de Estudos e Pesquisas Educacionais Anísio Teixeira, 2003. p. 115-128. Disponível em: <http://www. inep.gov.br/download/catalogodinamico/titulosavulsos/ 2003/acoesafirmativas. pdf>. Acesso em: 25 mai. 2007.

A difícil tarefa de definir quem é negro no Brasil. Estudos Avançados, São Paulo, v. 18, n. 50, p. 51-57. 2004.

OLIVEIRA, D. C.; MARQUES, S. C.; GOMES, A. M. T.; TEIXEIRA, M. C. $T$. V. Análise das evocações livres: uma técnica de análise estrutural das representações sociais. In: A. S. P. MOREIRA; B. V. CAMARGO; J. C. JESUÍNO; S. M. NÓBREGA (Orgs.). Perspectivas teóricometodológicas em representações sociais. J oão Pessoa: Editora UFPB, 2005. p. 573-603. 
SILVA, G. M. D. ações afirmativas no Brasil e na África do Sul. Tempo Social. v. 18, n. 2, p. 131-165, 2006.

SILVÉRIO, V. R. Ação afirmativa e o combate ao racismo institucional no Brasil. Cadernos de Pesquisa, São Paulo, n. 117, p. 219-246, 2003.

TRAGTENBERG, M. H. R.; BASTOS, J. L. D.; NOMURA, L. H.; PERES, M. A. Como aumentar a proporção de estudantes negros na universidade? Cadernos de Pesquisa, São Paulo, v. 36, n. 128, p.473-495, 2006.

VALENTE, A. L. Os negros, a educação e as políticas de ação afirmativa. Revista Brasileira de Educação, Rio de Janeiro, n. 19, p. 76-86, 2002.

VERGĖS. P. Approche du noyau central: propriétés quantitatives et structurales. In: $\mathrm{CH}$. GUIMELLI (Ed.) Structures et transformations des représentations sociales. Lausane: Delachaux et Niestlé, 1994. p. 233-253.

A evocação do dinheiro: um método para a definição do núcleo central de uma representação. In: A. S. P. MOREIRA; B. V. CAMARGO; J. C. JeSUÍNO; S. M. NÓBREGA (Orgs.). Perspectivas teórico-metodológicas em representações sociais. J oão Pessoa: Editora UFPB, 2005. p. 471-488.

WAGNER, W. Socio-gênese e características das representações sociais. In: MOREIRA, A. P.; OLIVEIRA, D. C. (Orgs.) Estudos interdisciplinares de representações sociais. Goiânia: $A B$ Editora, 1998. p.16-26.

\author{
Endereço para correspondência \\ Denis Giovani Monteiro Naiff \\ Universidade Federal Rural do Rio de Janeiro/UFRRJ, Instituto de Educação, BR 465 \\ Km 7, CEP 23900-000, Centro, Seropédica-RJ, Brasil \\ Endereço eletrônico: dnaiff@ufrrj.br \\ Luciene Alves Miguez Naiff \\ Universidade Salgado de Oliveira/UNIVERSO, Rua marcehal Deodoro 211, Bloco C \\ 2ㅇ andar, CEP 24030-060, Centro, Niterói-RJ, Brasil \\ Endereço eletrônico: lunaiff@hotmail.br \\ Marcos Aguiar de Souza \\ Universidade Federal Rural do Rio de Janeiro/UFRRJ, Instituto de Educação, BR 465 \\ Km 7, CEP 23900-000, Centro, Seropédica-RJ, Brasil \\ Endereço eletrônico: maquiarsouza@uol.com.br
}

Recebido em: 13/11/2007

Aceito para publicação em: 09/01/2008

Editor responsável: Anna Paula Uziel

\title{
Notas
}

*Doutor em Psicologia Social

** Doutora em Psicologia Social

*** Doutor em Psicologia 